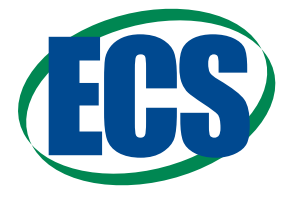

Jes Focus Issue on Proton Exchange Membrane Fuel Cell (PEMFC) Durability

\title{
Sb-Doped $\mathrm{SnO}_{2}$ Aerogels Based Catalysts for Proton Exchange Membrane Fuel Cells: Pt Deposition Routes, Electrocatalytic Activity and Durability
}

\author{
G. Ozouf, ${ }^{1}$ G. Cognard, ${ }^{2,3}$ F. Maillard, ${ }^{2,3, *}$ M. Chatenet, $\oplus^{1,2,3,4, *}$ L. Guétaz, ${ }^{5,6}$ \\ M. Heitzmann, ${ }^{5,6}$ P. A. Jacques, ${ }^{5,6}$ and C. Beauger $\oplus^{1, z}$ \\ ${ }^{I}$ MINES ParisTech, PSL Research University PERSEE, Centre procédés, énergies renouvelables et systèmes \\ énergétiques, Sophia Antipolis 06904, France \\ ${ }^{2}$ University Grenoble Alpes, Grenoble-INP, LEPMI, F-38000 Grenoble, France \\ ${ }^{3}$ CNRS, LEPMI, F-38000 Grenoble, France \\ ${ }^{4}$ French University Institute (IUF), Paris, France \\ ${ }^{5}$ University Grenoble Alpes, Grenoble F-38000, France \\ ${ }^{6}$ CEA, LITEN, F-38054 Grenoble, France
}

Tin dioxide is a promising catalyst support to improve the stability of proton-exchange membrane fuel cells (PEMFC) cathodes at high voltages. However, optimizing the catalytic activity for the oxygen reduction reaction (ORR) of tin dioxide based electrocatalyst still remains challenging. In this study, an antimony doped tin dioxide (ATO) aerogel featuring suitable physico-chemical properties for application at a PEMFC cathode was successfully synthetized. Two platinum nanoparticles deposition methods were tested and compared. One is a chemical reduction route (using ethylene glycol, EG), the other uses ultraviolet (UV) irradiation followed by different thermal post-treatments. Electrocatalysts structure and morphology were analyzed by X-ray diffraction (XRD) and transmission electron microscopy (TEM) experiments. The highest ORR mass activity measured in liquid electrolyte at $25^{\circ} \mathrm{C}$ was obtained for Pt/ATO from EG method (32 $\mathrm{A} \mathrm{g} \mathrm{gt}_{\mathrm{Pt}}{ }^{-1}$ versus $27 \mathrm{~A} \mathrm{~g}_{\mathrm{Pt}}{ }^{-1}$ for a reference Pt/HSAC $40 \mathrm{wt} \%$ ). Pt/ATO turned out to be more stable than Pt/HSAC during an accelerated stress test composed of 5,000 potential cycles between 1.0 and $1.5 \mathrm{~V}$ vs. RHE at $80^{\circ} \mathrm{C}$.

(C) The Author(s) 2018. Published by ECS. This is an open access article distributed under the terms of the Creative Commons Attribution 4.0 License (CC BY, http://creativecommons.org/licenses/by/4.0/), which permits unrestricted reuse of the work in any medium, provided the original work is properly cited. [DOI: 10.1149/2.0041806jes]

(cc) BY

Manuscript submitted December 20, 2017; revised manuscript received February 1, 2018. Published February 14, 2018. This paper is part of the JES Focus Issue on Proton Exchange Membrane Fuel Cell (PEMFC) Durability.

Proton-exchange membrane fuel cells (PEMFCs) are energy converters producing electricity, heat and water from hydrogen and oxygen gases. ${ }^{1,2}$ This technology can be scaled up within a large range of power from a few $\mathrm{W}$ to hundreds of $\mathrm{kW}$ and operates at low temperatures $\left(80^{\circ} \mathrm{C}\right)$ thus allowing quick starts. It is tolerant to carbon dioxide $\left(\mathrm{CO}_{2}\right)$ and so can be fed by air and not only by pure oxygen $\left(\mathrm{O}_{2}\right)$. State-of-the-art PEMFC anodes and cathodes both require platinum $(\mathrm{Pt})$ to electrocatalyze the hydrogen oxidation reaction (HOR) and the oxygen reduction reaction (ORR), respectively. The electrocatalysts are usually Pt nanoparticles supported on high-surface area carbon ca. 3-4 nm in diameter. The support enables efficient Pt nanoparticle deposition, ionomer insertion, (liquid) water and gas flow management.

Although the initial performances of PEMFCs are now acceptable for industrial deployment, their lifetime and reliability still need to be improved to render them economically competitive with batteries and internal combustion engines. Significant performance losses are indeed observed during PEMFC operation, due to the degradation of electrode materials. For example, a loss of electrochemical surface area (ECSA) is monitored over time, which is mainly caused by migration/aggregation of $\mathrm{Pt}$ nanoparticles on the carbon support, ${ }^{3,4} \mathrm{Pt}$ dissolution/redeposition (electrochemical Ostwald ripening) ${ }^{5-8}$ and/or catalyst support corrosion leading to detachment of Pt nanoparticles. ${ }^{9-14}$ The latter process, the electrochemical carbon oxidation reaction (COR), is thermodynamically favorable at potentials higher than 0.2 $\mathrm{V}$ vs. the reversible hydrogen electrode (RHE) according to Reaction 1 :

$$
\mathrm{C}+2 \mathrm{H}_{2} \mathrm{O} \rightarrow \mathrm{CO}_{2}+4 \mathrm{H}^{+}+4 \mathrm{e}^{-} \quad E^{\circ}=0.207 \mathrm{~V} \text { vs. } \mathrm{RHE}
$$

At temperatures below $100^{\circ} \mathrm{C}$ and potential below $1.0 \mathrm{~V}$ vs. RHE, the COR kinetics is considered to be reasonably slow. However, rapid and significant carbon weight loss has been monitored above

\footnotetext{
*Electrochemical Society Member.

${ }^{\mathrm{z}}$ E-mail: christian.beauger@mines-paristech.fr
}

$1.0 \mathrm{~V}$ vs. RHE. ${ }^{9-11}$ The COR is more intense during start/stop or fuel starvation events, for which high potential values are reached at the cathode side $\left(E>1.5 \mathrm{~V}\right.$ vs. RHE) ${ }^{15-17}$ Carbon corrosion occurring at the cathode side can therefore be severe. ${ }^{12}$ To improve the durability of PEMFC cathodes, carbon-free supports have been proposed as an alternative to carbon blacks. Among metal oxides, which are thermodynamically stable in PEMFC cathode operating conditions, tin dioxide $\left(\mathrm{SnO}_{2}\right)$ appears to be the most promising. ${ }^{18-20}$ $\mathrm{SnO}_{2}$ is a $n$-type semi-conductor but its electronic conductivity can be enhanced by doping with hypervalent donor elements. ${ }^{21-23}$ Most of the dopant elements added to the $\mathrm{SnO}_{2}$ matrix are known to inhibit particle growth and modify the material morphology. ${ }^{21,24} \mathrm{Nb}^{25-28}$ or $\mathrm{Sb}_{-}{ }^{25,26,29-37}$ doped $\mathrm{SnO}_{2}$ materials have already been tested as catalyst support. $\mathrm{Pt} / \mathrm{SnO}_{2}$-based electrocatalysts have demonstrated high mass activity for the ORR, sometimes surpassing that of $\mathrm{Pt} / \mathrm{C}$ electrocatalysts. Kakinuma et al. prepared $3.0 \mathrm{~nm}$-sized Pt nanoparticles supported on $\mathrm{Sb}$-doped or Nb-doped $\mathrm{SnO}_{2} \cdot{ }^{26,31}$ Both the ORR mass activity and the stability of their electrocatalysts measured in rotating disk electrode (RDE) configuration were higher than that of a reference $\mathrm{Pt} / \mathrm{C}$ material. The $\mathrm{Pt}$ nanoparticles $(3.1 \mathrm{~nm})$ deposited onto Ta-doped $\mathrm{SnO}_{2}$ by Senoo et al. (Pt loading $15.8 \mathrm{wt} \%$ ) also showed a high mass activity for the ORR and excellent durability. ${ }^{38}$ This was ascribed to strong interactions between $\mathrm{Pt}$ and the $\mathrm{SnO}_{2}$-based support (Strong Metal Support Interactions, SMSI). ${ }^{39-41}$ It is well established that SMSI modifies the electronic structure of Pt. ${ }^{42}$ However, a recent study has shown that steric effects might also be the reason of the enhanced ORR kinetics (lower activation barrier). ${ }^{43}$ A number of works have demonstrated the interest of metal oxides to support Pt nanoparticles for use at PEMFC cathodes. However, only in very few studies did the support present a texture compatible with good Pt nanoparticle deposition, ionomer insertion, and gas and water mass-transport.

The work presented here fills this gap; it is dedicated to the deposition process of $\mathrm{Pt}$ on $\mathrm{Sb}$-doped tin dioxide aerogel (ATO aerogel). Due to their remarkable morphology and texture, carbon aerogels have 
already proven their ability to efficiently support catalysts for PEMFC applications. ${ }^{44,45}$ ATO aerogels are composed of aggregated particles forming a three-dimensional network, very similar to that of carbon aerogels. This material features a relatively high electronic conductivity $\left(0.12 \mathrm{~S} \mathrm{~cm}^{-1}\right)$, and a morphology adapted to PEMFC application, i.e. a reasonably high specific surface area of $85 \mathrm{~m}^{2} \mathrm{~g}^{-1}$ (considering the skeleton density of $\mathrm{SnO}_{2}$ ) and a bimodal pore size distribution centered on $20 \mathrm{~nm}$ and $45 \mathrm{~nm}$. These ATO aerogel-based electrocatalysts have been characterized and their electrocatalytic activity toward oxygen reduction reaction evaluated in previous works. ${ }^{29,30}$ In this study, we focus on the impact of the Pt reduction route and that of thermal post-treatments on the physico-chemical and electrochemical properties of the obtained Pt/ATO electrocatalysts. The results show that the deposition process affects the Pt nanoparticle size, the surface of exposed crystallographic facets, and their crystallinity. To evaluate the most promising deposition process, an accelerated stress test (AST) mimicking start/stop cycles was performed, and the durability of Pt/ATO electrocatalysts compared with that of a reference $\mathrm{Pt} / \mathrm{C}$.

Herein, two Pt deposition methods are compared. The first one, adapted from the literature $e^{20,27,33,34,46-49}$ is a modified polyol route using ethylene glycol as a solvent and reducing agent (EG method). The second deposition method is an incipient wetness impregnation method of ATO with a $\mathrm{Pt}$ salt $\left(\mathrm{H}_{2} \mathrm{PtCl}_{6}, 6 \mathrm{H}_{2} \mathrm{O}\right)$. The reduction is performed either in a reducing atmosphere $\left(\mathrm{H}_{2} / \mathrm{N}_{2} 5\right.$ vol.\%) or under ultraviolet (UV) irradiation. The effect of thermal post-treatments in different atmospheres (oxidizing or reducing) was also investigated after UV irradiation.

\section{Experimental}

Catalyst support synthesis route.-The Sb-doped $\mathrm{SnO}_{2}$ aerogel was synthesized by a sol-gel route described in a former work. ${ }^{21}$ Briefly, tin (IV) isopropoxide (Alfa Aesar) and antimony (III) isopropoxide (Alfa Aesar), were mixed in water and isopropanol, using nitric acid as a catalyst. Sol-gel parameters were chosen as follows: $\mathrm{HNO}_{3} / \mathrm{Sn}=0.072 \mathrm{~mol} / \mathrm{mol}, \mathrm{H}_{2} \mathrm{O} / \mathrm{Sn}=3.06 \mathrm{~mol} / \mathrm{mol}$ and $\mathrm{iPrOH} / \mathrm{Sn}$ $=119 \mathrm{~mol} / \mathrm{mol}$. The gels formed were aged at room temperature for $48 \mathrm{~h}$, washed with isopropanol 3 times a day during 2 days, and then dried in supercritical $\mathrm{CO}_{2}\left(80\right.$ bars, $\left.40^{\circ} \mathrm{C}\right)$. The resulting aerogels were calcined in air at $600^{\circ} \mathrm{C}$ for $5 \mathrm{~h}$.

Pt Deposition protocols.-Two Pt deposition methods were used in this study. In the EG method, Pt nanoparticles are synthesized in solution before deposition on the support whereas in the other one they are formed directly on the support.

In the EG method, ethylene glycol acts both as a reducing agent and a stabilizer of the formed Pt nanoparticles. $140 \mathrm{mg} \mathrm{of} \mathrm{H}_{2} \mathrm{PtCl}_{6}$, $6 \mathrm{H}_{2} 0$ were dissolved in $100 \mathrm{~mL}$ of EG. The $\mathrm{pH}$ was adjusted to 10 by adding appropriate amounts of $\mathrm{NaOH}$, and the solution was refluxed at $160^{\circ} \mathrm{C}$ for $30 \mathrm{~min}$ in argon. ATO previously dispersed in $4 \mathrm{~mL}$ of water was then added and the $\mathrm{pH}$ was reduced to 2 by addition of $\mathrm{H}_{2} \mathrm{SO}_{4}$ (Suprapur, Merck). The dispersion was left at room temperature under magnetic stirring during $24 \mathrm{~h}$ before filtration and copious washing with Milli-Q grade water.

In the incipient wetness impregnation method, $155 \mathrm{mg}$ of ATO (dispersed in $4 \mathrm{~mL}$ of water) were impregnated with $10 \mathrm{~mL}$ of an aqueous solution of $\mathrm{H}_{2} \mathrm{PtCl}_{6}, 6 \mathrm{H}_{2} \mathrm{O}\left(8.2 \mathrm{mg} \mathrm{mL} \mathrm{m}^{-1}\right)$. The dispersion was heated at $60^{\circ} \mathrm{C}$ under magnetic stirring until total solvent evaporation. The resulting powder was heat-treated in air at $350^{\circ} \mathrm{C}$ for 1 $\mathrm{h}$. The powder was then washed with water until elimination of all chloride $\left(\mathrm{Cl}^{-}\right)$ions from the filtrate $\left(\mathrm{Cl}^{-}\right.$ions were detected from $\mathrm{AgCl}$ precipitation with $\mathrm{AgNO}_{3}$ solution). The $\mathrm{PtO}$ colloids formed after the heat-treatment in air were then reduced by calcination in $\mathrm{H}_{2} / \mathrm{N}_{2}\left(5\right.$ vol. \%) for $3 \mathrm{~h}$ at $200^{\circ} \mathrm{C}$ (sample I-1). Alternatively, UV irradiation was used (mercury lamp, $500 \mathrm{~W}, 6285$, from Newport). Different irradiation durations were tested: 1,3 and $5 \mathrm{~h}$ (samples I-2, I-3 and I-4). Lastly, different thermal post-treatments were finally evaluated to complete Pt nanoparticles reduction or crystallization:

\section{Table I. Reduction routes and thermal post-treatments applied to} Pt/ATO (impregnation/reduction method).

\begin{tabular}{clll} 
Samples & Reduction & Calcination & Annealing \\
\hline I-1 & $\mathrm{H}_{2}\left(200^{\circ} \mathrm{C}, 3 \mathrm{~h}\right)$ & & \\
I-2 & UV (300W, 1 h) & & \\
I-3 & UV (300W, 3 h) & & \\
I-4 & UV (300W, 5 h) & & \\
I-5 & UV (300W, 3 h) & $\mathrm{H}_{2}\left(200^{\circ} \mathrm{C}, 1 \mathrm{~h}\right)$ & \\
I-6 & UV (300W, 3 h) & $\mathrm{H}_{2}\left(200^{\circ} \mathrm{C}, 3 \mathrm{~h}\right)$ & \\
I-7 & UV (300W, 3 h) & Air $\left(400^{\circ} \mathrm{C}, 2 \mathrm{~h}\right)$ & \\
I-8 & UV (300W, 3 h) & $\mathrm{H}_{2}\left(200^{\circ} \mathrm{C}, 3 \mathrm{~h}\right)$ & Air $\left(400^{\circ} \mathrm{C}, 2 \mathrm{~h}\right)$
\end{tabular}

i) calcination in $\mathrm{H}_{2} / \mathrm{N}_{2}$ at $200^{\circ} \mathrm{C}$ for 1 or $2 \mathrm{~h}$ (samples I-5 and I-6), ii) calcination in air at $400^{\circ} \mathrm{C}$ for $2 \mathrm{~h}$ (sample I-7) or iii) calcination in $\mathrm{H}_{2} / \mathrm{N}_{2}\left(200^{\circ} \mathrm{C}, 3 \mathrm{~h}\right)$ followed by annealing in air at $400^{\circ} \mathrm{C}$ for $3 \mathrm{~h}$ (sample I-8). The reduction routes and corresponding sample names are summarized in Table I.

Characterization.-X-ray diffraction (XRD) measurements were performed using an X'Pert pro Philips diffractometer $(\mathrm{Cu} \mathrm{K} \alpha, \lambda=$ $1.5405 \AA$ ). The diffractometer was operated at $45 \mathrm{kV}$ and $30 \mathrm{~mA}$. The data were collected in steps of $0.05^{\circ}$ from $20^{\circ}$ to $90^{\circ}$ in $2-\theta$ mode with a Pixcel counter.

The distribution and dispersion of Pt nanoparticles onto the ATO support were analyzed by HRTEM (high-resolution transmission electron microscopy) or HAADF/STEM (high-angular dark-field scanning TEM) using a spherical aberration probe-corrected FEI-Themis microscope operating at $200 \mathrm{kV}$ and equipped with a Super-X system (4 Silicon Drift Detectors) optimized for high-speed X-ray energydispersive spectrometry (X-EDS) measurements. For these TEM analyses, each electrocatalyst powder was dispersed in isopropanol and a drop was deposited on a lacey-carbon TEM grid.

TEM images of Pt/HSAC were acquired using a JEOL 2010 microscope operated at $200 \mathrm{kV}$.

The Pt weight fractions were determined by atomic absorption spectrometry (AAS) measurements using solutions resulting from the digestion of the electrocatalyst samples (Pt/ATO and Pt/C) in concentrated aqua regia during 20 hours. The digestion solution was centrifuged, diluted and injected into the AAS (PinAAcle 900T from Perkin Elmer) using a mixture of air and acetylene. The Pt weight fraction was calculated based on a calibration curve, obtained with standard solutions prepared from Pt single element AAS standard solution (1,000 ppm, RotiStar, Roth).

The electrochemical measurements were performed using an $\mathrm{Au}-$ tolab PGSTAT20 and a rotating disk electrode (RDE). Catalytic inks were prepared by dispersing the catalyst and Nafion in ultrapure water. Inks were formulated to obtain a constant $\mathrm{Pt}$ loading on the working electrode (WE). The quantity of Nafion was adjusted to obtain the same film thickness $\left(2 \mathrm{mg}_{\text {Nafion }} \mathrm{m}_{\text {support }}{ }^{-2}\right)$ whatever the specific surface area of the supports. $80 \mu \mathrm{L}$ of the catalytic suspension were deposited on the working electrode (glassy carbon disk, geometric area: $\left.0.196 \mathrm{~cm}^{2}\right)$ in two steps $(40 \mu \mathrm{L}$ each) targeting a final loading of $60 \mu \mathrm{g}_{\mathrm{Pt}} \mathrm{cm}_{\text {geom }}{ }^{-2}$. The deposits were then dried at $110^{\circ} \mathrm{C}$.

The catalytic activity measurements and the durability test were conducted in two different four-electrode electrochemical glass cells, a characterization and a degradation cell. For each of them, a glassy carbon plate was used as the counter-electrode (to avoid contamination of the working electrode by metal cations resulting from its dissolution), a Reversible Hydrogen Electrode (RHE) as the reference electrode and a Pt wire connected to the reference-electrode was used to filter the high frequency electrical noise. The electrolyte was a 0.1 $\mathrm{M} \mathrm{H}_{2} \mathrm{SO}_{4}$ solution freshly prepared from MQ-grade water (18.2 M $\Omega$ cm, 1-3 ppb TOC) and $\mathrm{H}_{2} \mathrm{SO}_{4}$ (Suprapur, Merck).

Cyclic voltammograms (CVs) were recorded between 0.05 and $1.23 \mathrm{~V}$ vs. RHE at a potential sweep rate of $v=0.1 \mathrm{~V} \mathrm{~s}^{-1}$ in Ar-saturated $0.1 \mathrm{M} \mathrm{H}_{2} \mathrm{SO}_{4}$. The Pt specific surface area $\left(S_{\mathrm{Pt}}\right)$ was 
(a)
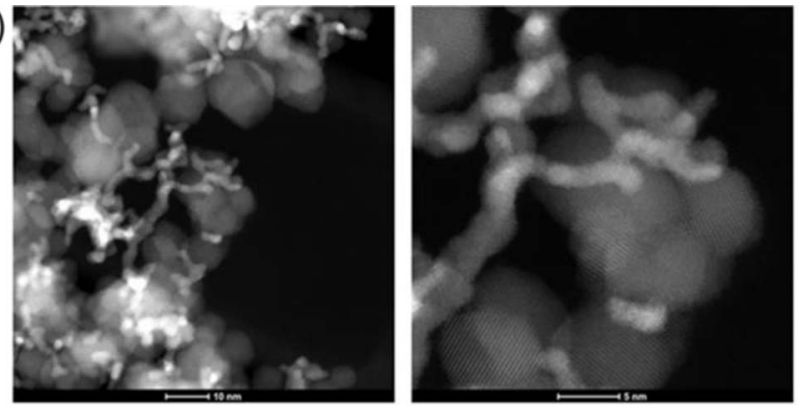

(b)

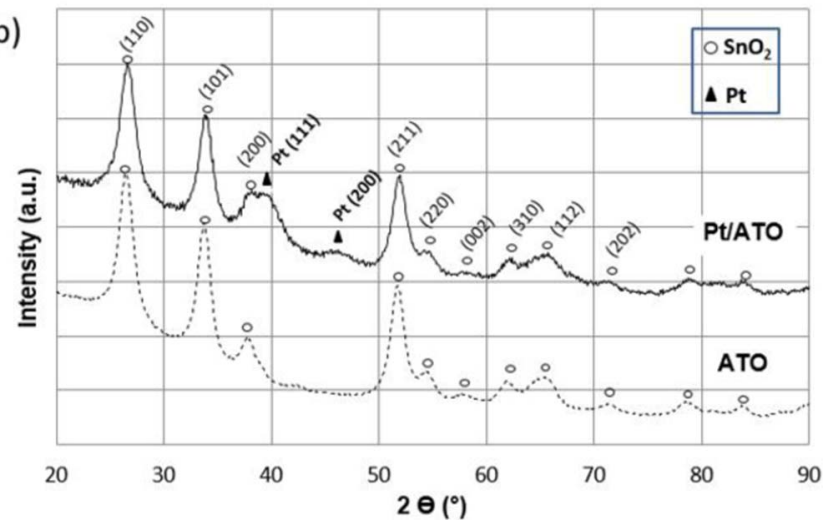

Figure 1. HAADF/STEM images at two magnifications (a) and XRD patterns (b) of ATO and Pt/ATO aerogels prepared using the EG method.

determined by coulometry of the under-potential desorption of $\mathrm{H}$ atoms $\left(\mathrm{H}_{\text {upd }}\right)$. The catalytic activity for the ORR was determined from $\mathrm{CV}$ s performed at a potential sweep rate of $v=0.005 \mathrm{~V} \mathrm{~s}^{-1}$ from 0.4 to $1.05 \mathrm{~V}$ vs. RHE at different rotating speeds $(400,900,1,600$ and 2,500 $\mathrm{rpm})$. The mass activities for the ORR at $E=0.9 \mathrm{~V}$ vs. RHE were calculated from the polarization curves in the positive-going potential sweep using the Koutecky-Levich method.

\section{Results and Discussion}

The efficiency of the two deposition protocols was evaluated by considering i) the structure and the morphology of the Pt nanoparticles (XRD, HRTEM and HAADF/STEM), ii) the specific surface area $\left(S_{\mathrm{Pt}}\right)$ and iii) the electrocatalytic activity for the oxygen reduction reaction (ORR) measured in RDE configuration. The stability of the most promising Pt/ATO electrocatalysts toward AST was also evaluated.

It is noteworthy on Figure 1 that the Pt nanoparticles deposited on the ATO aerogel surface by the EG method are essentially interconnected to form filaments. HRTEM images even suggest that the filaments actually consist of individual crystallites of 2 or $3 \mathrm{~nm}$ in diameter. Such an arrangement was not observed after similar deposition on carbon XC72. ${ }^{30}$ Considering the morphology described above (filament) it is not relevant to estimate the Pt nanoparticle size from the specific surface area data (the Pt nanoparticles are far from being spherical). XRD analysis confirmed the presence of Pt nanocrystallites. The Pt weight fraction estimated by AAS was $21 \mathrm{wt} \%$.

The Pt nanoparticles deposited using the incipient wetness impregnation method significantly differ from those obtained following EG method. In this method, ATO was first impregnated with the Pt salt precursor solution, and the resulting dispersion was dried at $60^{\circ} \mathrm{C}$ until total evaporation of the solvent. Different reduction routes were used.

After reduction in $\mathrm{H}_{2} / \mathrm{N}_{2}$ at $200^{\circ} \mathrm{C}$ for $3 \mathrm{~h}$, the XRD patterns evidenced Pt (111) and Pt (200) characteristic peaks on sample I-1 at $39.1^{\circ}$ and $45.8^{\circ}$ respectively (see Figure 2 ). As already reported by Kamiuchi et al., ${ }^{40}$ characteristic peaks of an intermetallic compound, PtSn, were also observed at $2 \Theta=29^{\circ}, 42^{\circ}$ and $44^{\circ}$. The authors attributed the presence of this compound to the reduction of the tin oxide phase. They also observed the formation of core-shell nanoparticles, $\mathrm{Pt} @ \mathrm{SnO}_{2}$, resulting from partial oxidation of the $\mathrm{Sn}$ atoms

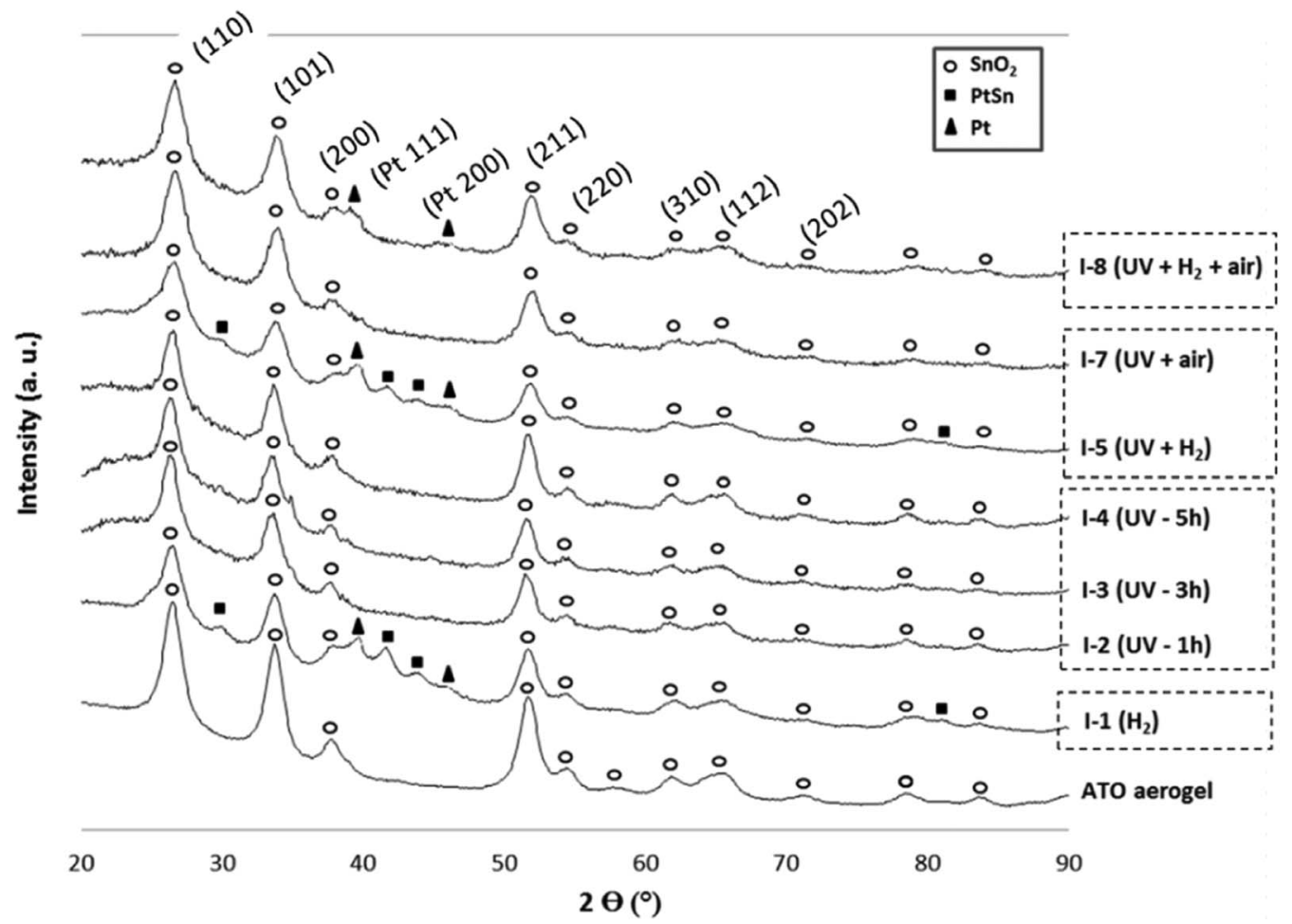

Figure 2. XRD patterns of ATO and Pt/ATO aerogels obtained from the incipient wetness impregnation method after different reduction routes and heat-treatments. 

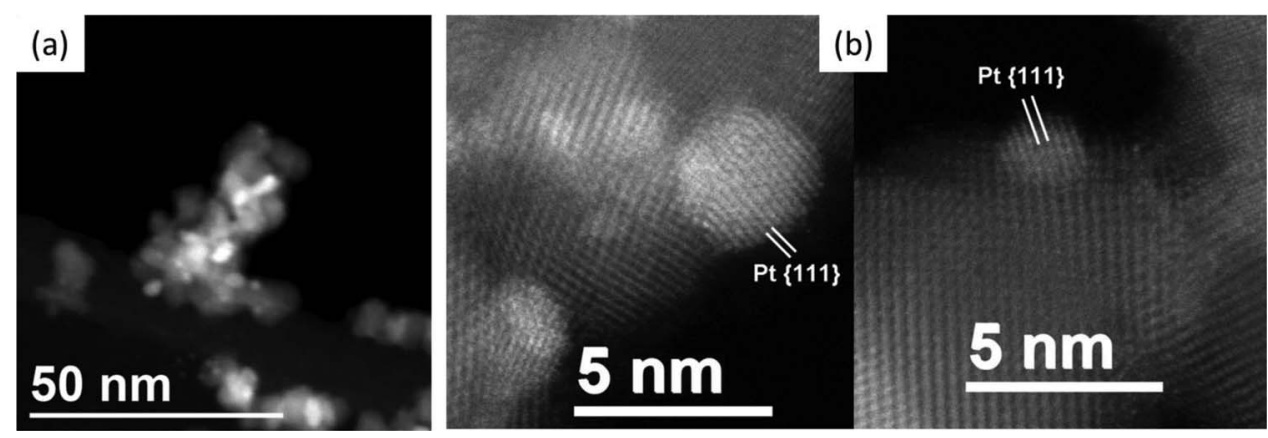

Figure 3. HAADF/STEM images of Pt/ATO aerogel after heat-treatment in reducing atmosphere, I-1 (a), Pt nanoparticles lying at the edge of a SnO ${ }_{2}$ grain (b). Neither $\mathrm{SnO}_{2}$ nor PtSn shell is visible around the nanoparticles.

from the intermetallic compound. This phenomenon has also been reported for $\mathrm{Pt} / \mathrm{WO}_{3}$ by Micoud et al. ${ }^{50}$ It is driven by the difference in surface energy between the MOx support and the Pt nanoparticles. During the calcination in a reducing atmosphere, sub-stoichiometric metal oxides are formed. These are highly mobile and encapsulate the $\mathrm{Pt}$ nanoparticles to minimize the total surface energy of the $\mathrm{Pt} / \mathrm{WO}_{3}$ compound. In this study, neither X-EDS Sn elemental maps nor high resolution HAADF/STEM images acquired on Pt nanoparticles lying at the edge of the $\mathrm{SnO}_{2}$ particle (see Figure 3) provided evidence of Pt core@ $\mathrm{SnO}_{2}$ nanoparticle structure or PtSn phase formation. These analyses cannot be generalized to a lot of Pt nanoparticles due to the difficulty of detecting PtSn phase when Pt nanoparticles are superimposed to the $\mathrm{SnO}_{2}$ support. Neither the size of the Pt nanoparticles nor their distribution was homogeneous. Some relatively large Pt nanoparticles, with a diameter of about 6 to $7 \mathrm{~nm}$, were observed together with smaller ones of 1 to $2 \mathrm{~nm}$ in diameter. Moreover, some Pt agglomerates appeared in some regions.

As already reported, Pt nanoparticles can be deposited on MOx supports using photoreduction. ${ }^{51}$ The hydrogen reduction step was thus replaced by UV irradiation. According to the analysis of TEM images, the duration of UV irradiation had no influence on the size distribution of the Pt nanoparticles ${ }^{29}$ (I-2, I-3 and I-4). Whatever the irradiation time ( $1 \mathrm{~h}, 3 \mathrm{~h}$ or $5 \mathrm{~h}$ ), Pt nanoparticles were perfectly distributed on the ATO support. A homogeneous distribution of particles with diameters around $2 \mathrm{~nm}$ was observed after $3 \mathrm{~h}$ of irradiation (sample I-3, see Figure 4a).

Nevertheless, no characteristic peak of Pt could be detected by XRD on samples I-2 to I-4 (see Figure 2). This may be rationalized by considering that the Pt nanoparticles are either (i) too small to be evidenced with XRD (not likely, as similar Pt nanoparticle sizes usually lead to clear XRD patterns), (ii) amorphous, or (iii) still not reduced after $5 \mathrm{~h}$ of photoreduction (not likely, as TEM images provide evidence of Pt nanoparticles, see Figure 4). To determine which hypothesis is valid, thermal post-treatments were performed to complete the reduction and/or the crystallization of the Pt nanoparticles. These consist in thermal treatments performed in hydrogen and air (samples I-5 to I-8, Table I).

After post-treatment in $\mathrm{H}_{2} / \mathrm{N}_{2}$ for $1 \mathrm{~h}$ at $200^{\circ} \mathrm{C}$ (I-5), Pt and PtSn phases were detected by XRD, as in the case of I-1 (reduction under $\mathrm{H}_{2} / \mathrm{N}_{2}$ only). The Pt nanoparticles were still evenly distributed on the ATO surface but their size distribution was broader: particles of about $3 \mathrm{~nm}$ in diameter and others of less than $1 \mathrm{~nm}$ were observed (see Figure $4 b$ ). This clearly indicates that the two-step reduction has an influence on both the structure and morphology of the Pt nanoparticles. They are indeed smaller than after a single reduction step in $\mathrm{H}_{2}$ (sample I-1) and more crystalline than after a single reduction by UV irradiation (sample I-3). This kind of post-treatment is beneficial considering the foreseen application. However, the presence of PtSn intermetallic compound may influence the electrocatalytic activity for the ORR.

To avoid the formation of the PtSn phase while attempting to crystallize the Pt, calcination was performed in air (sample I-7). A temperature of $400^{\circ} \mathrm{C}$, instead of $200^{\circ} \mathrm{C}$, was chosen to preserve the support morphology (previously calcined at $600^{\circ} \mathrm{C}$ for crystallization). After this treatment, still no characteristic Pt patterns could be detected (see Figure 2, I-7). Pt nanoparticles were however clearly observed on TEM images (Figure 4c). Their sizes were comparable to those observed after UV irradiation and calcination under $\mathrm{H}_{2} / \mathrm{N}_{2}$ (sample I-5). Despite a higher calcination temperature $\left(400^{\circ} \mathrm{C}\right.$ vs. $\left.200^{\circ} \mathrm{C}\right)$, this kind of heat-treatment in air was not efficient enough to crystallize the Pt nanoparticles.

After post-treatment in $\mathrm{H}_{2} / \mathrm{N}_{2}$, Pt nanoparticles were well crystallized and evenly distributed over the ATO surface, with diameters ranging from 1 to $3 \mathrm{~nm}$. To re-oxidize and separate the $\mathrm{Pt}$ and $\mathrm{Sn}$ phases from the PtSn intermetallic compound, the sample was first calcined in $\mathrm{H}_{2} / \mathrm{N}_{2}$ and then annealed in air at $400^{\circ} \mathrm{C}$ for $2 \mathrm{~h}$. The XRD patterns of the resulting sample (I-8) display only the characteristic peaks of metallic Pt (Figure 2, I-8). In addition, no significant difference in Pt particle size was observed compared to samples I-5 and I-7 (Figure 4d).

To conclude, from structural and morphological points of view, heat treatments performed under different atmospheres have a strong influence on the morphology and nature of Pt nanoparticles (metal or
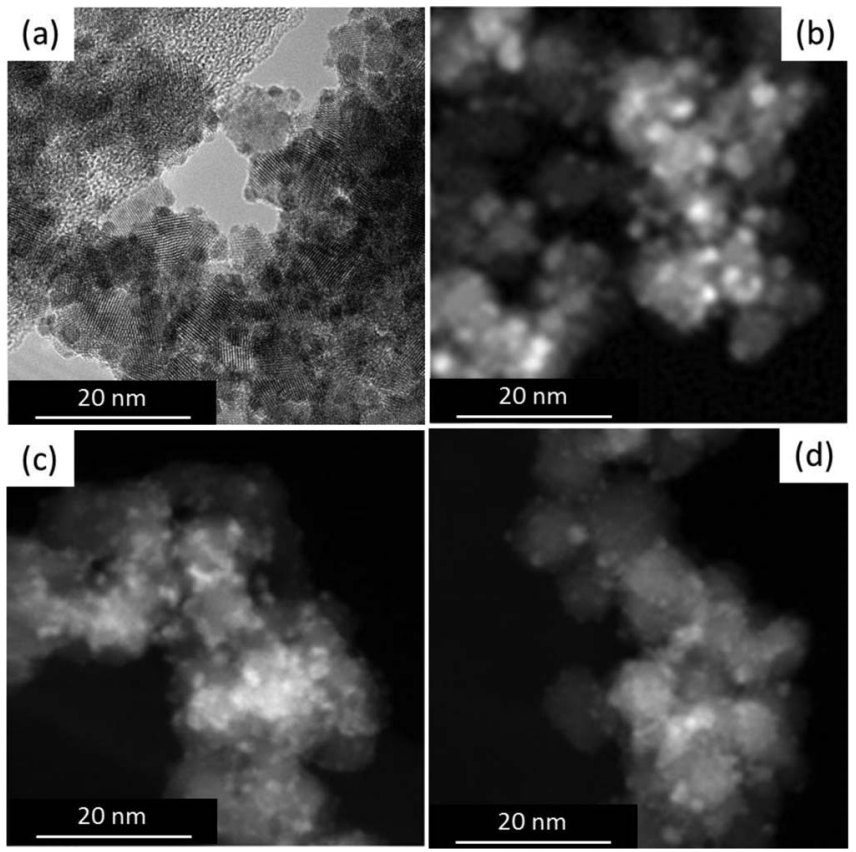

Figure 4. TEM micrographs of Pt/ATO aerogels after UV reduction ( $3 \mathrm{~h}$ ) I-3 (a), HAADF/STEM image of Pt/ATO aerogels after UV irradiation + heat treatment: $\mathrm{H}_{2}\left(200^{\circ} \mathrm{C}, 1 \mathrm{~h}\right), \mathrm{I}-5$ (b), air $\left(400^{\circ} \mathrm{C}, 2 \mathrm{~h}\right), \mathrm{I}-7$ (c) and $\mathrm{H}_{2}\left(200^{\circ} \mathrm{C}\right.$, $3 \mathrm{~h})+\operatorname{air}\left(400^{\circ} \mathrm{C}, 2 \mathrm{~h}\right), \mathrm{I}-8$ (d). 

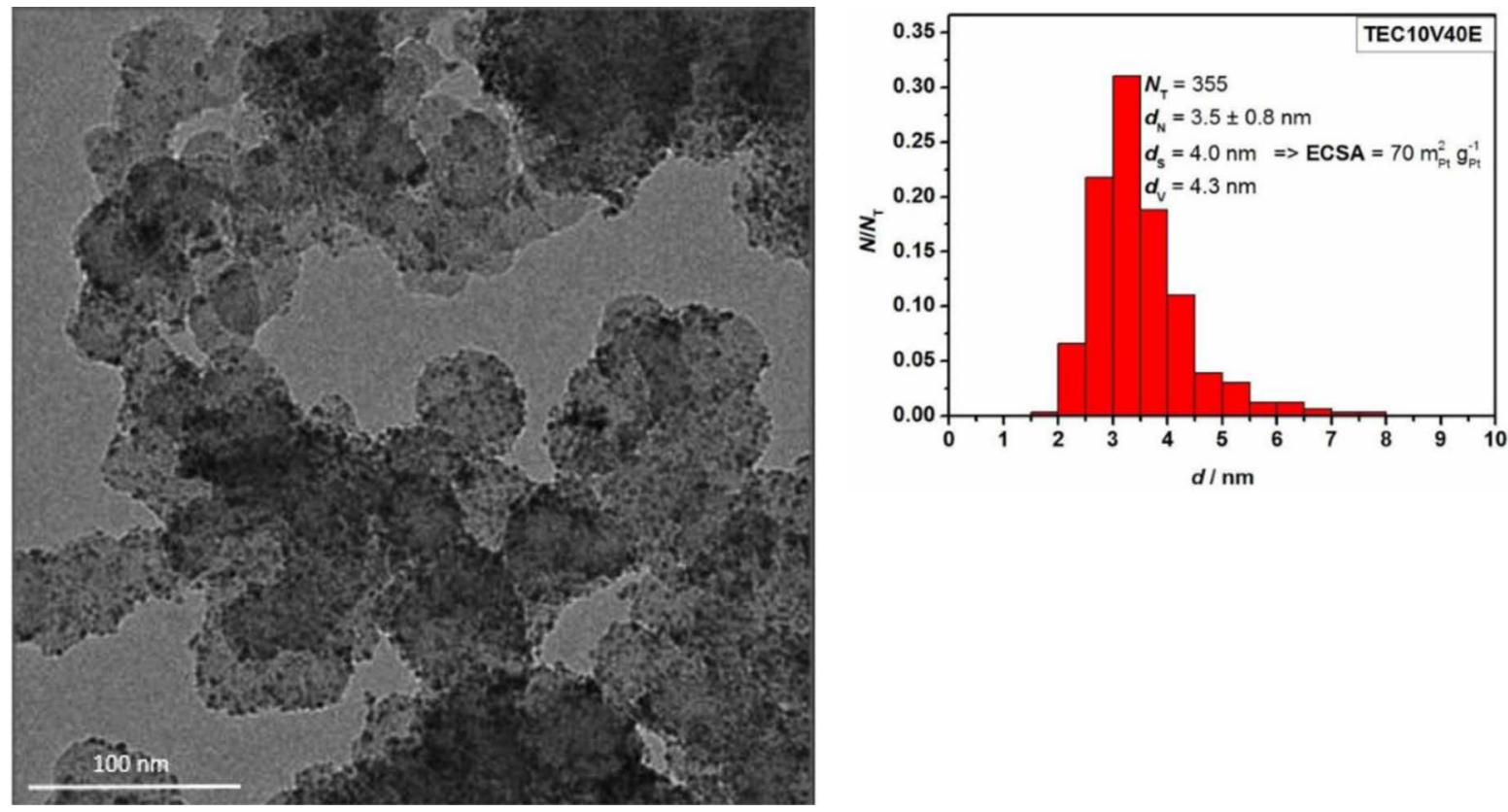

Figure 5. TEM image and Pt particle size distribution of the Pt/HSAC $40 \mathrm{wt} \%$ catalyst used as reference (TKK TEC10V40E).

oxide, crystallized or amorphous). A promising electrocatalyst (from a materials point of view) can be obtained by UV irradiation, followed by calcination in $\mathrm{H}_{2} / \mathrm{N}_{2}$ and annealing in air (sample I-8).

The $\mathrm{Pt}$ weight fraction obtained after the incipient wetness impregnation method was estimated as $19 \mathrm{wt} \%$ on sample I-3 by AAS. Since post-thermal treatments performed on I-3 are unlikely to modify the Pt loading of the resulting samples (I-4 to I-8), we assumed that all samples obtained from the incipient wetness impregnation method feature a similar loading (19 wt \%).

Figure 5 displays TEM image and the associated particle size distribution of the reference Pt/HSAC catalyst. The Pt nanoparticles are evenly distributed on the carbon support, and the mean particle size range between 3 and $4 \mathrm{~nm}$.

Electrochemical measurements.-The Pt specific surface area $\left(S_{\mathrm{Pt}}\right)$ and the ORR mass activity $\left(\mathrm{MA}_{0.9 \mathrm{~V}}\right)$ at $E=0.9 \mathrm{~V}$ vs. RHE of different Pt/ATO aerogel samples were determined in RDE configuration and benchmarked to those of Pt/HSAC.

Initial performance of the different Pt/ATO aerogel electrocatalysts.-Figure 6 compares the base CVs of Pt/ATOEG and Pt/HSAC (Figure 6a) and the different Pt/ATO-I samples (Figure 6b). The corresponding Pt specific surface area $\left(S_{\mathrm{Pt}}\right)$ and ORR mass activities determined at $0.9 \mathrm{~V}$ vs. RHE $\left(\mathrm{MA}_{0.9 \mathrm{~V}}\right)$ are displayed in Table II.

In the positive-going potential sweep, the CVs of Pt/ATO-EG electrocatalyst obtained by the polyol route and of the reference Pt/HSAC electrocatalyst feature the adsorption/desorption of under-potential deposited $\mathrm{H}\left(\mathrm{H}_{\text {upd }}\right)$ between $0.05<E<0.40 \mathrm{~V}$ vs. RHE and the formation of surface oxides $(\mathrm{OH} / \mathrm{O})$ at $0.75<E<1.2 \mathrm{~V}$ vs. RHE (Figure 6a). These Pt surface oxides are reduced between $1.2>E>$ $0.45 \mathrm{~V}$ vs. RHE on the reverse potential sweep. The positive shift of the surface oxide reduction peak observed for Pt/ATO-EG relative to that of Pt/HSAC suggests that larger Pt nanoparticles are present on Pt/ATO-EG, in agreement with TEM observations and the dependence of this peak position on the Pt nanoparticle size. ${ }^{52}$

Looking at Figure $6 \mathrm{a}$, the $\mathrm{H}_{\text {upd }}$ charge is obviously greater for $\mathrm{Pt} / \mathrm{HSAC}$ than for Pt/ATO-EG. The Pt specific surface area calculated from the coulometry of the $\mathrm{H}_{\text {upd }}$ desorption peaks amounts to $32 \mathrm{~m}^{2}$ $\mathrm{g}_{\mathrm{Pt}^{-1}}{ }^{-1}$ on Pt/ATO versus $72 \mathrm{~m}^{2} \mathrm{~g}_{\mathrm{Pt}}{ }^{-1}$ on Pt/HSAC.
Despite this smaller $S_{\mathrm{Pt}}$ value, the Pt/ATO-EG electrocatalyst features slightly higher ORR mass activity than the reference electrocatalyst (32 $\mathrm{A} \mathrm{g} \mathrm{gt}_{\mathrm{Pt}^{-1}}$ vs. $27 \mathrm{~A} \mathrm{~g}_{\mathrm{Pt}}{ }^{-1}$, respectively), in agreement with former literature findings. ${ }^{26,30,38}$ This is usually accounted for by considering a synergy between the Pt nanoparticles and the metal oxide support (SMSI) or preferential crystalline orientation of Pt nanoparticles and particle size effects although none of these phenomena were identified in this study.

The electrochemical signatures of the Pt/ATO-I samples strongly depend on the post-treatment (Figure 6b).

After photoreduction (sample I-3), $S_{\mathrm{Pt}}$ is very low, reaching only $6 \mathrm{~m}^{2} \mathrm{~g}_{\mathrm{Pt}}{ }^{-1}$. This is consistent with the XRD observations showing the absence of Pt diffraction patterns. These results confirm that UV irradiation at $300 \mathrm{~W}$ for 3 hours is not sufficient to fully reduce Pt. The thermal post-treatment in $\mathrm{H}_{2} / \mathrm{N}_{2}$ performed after UV irradiation (I-5 and I-6) is beneficial; $S_{\mathrm{Pt}}$ values are indeed significantly increased, in a manner scaling with the annealing time: 1 or $3 \mathrm{~h}$ lead to higher $\mathrm{S}_{\mathrm{Pt}}$, 13 and $14.5 \mathrm{~m}^{2} \mathrm{~g}_{\mathrm{Pt}}{ }^{-1}$, respectively for samples I-5 and I-6. Annealing in air after UV irradiation (I-7) provided a surprisingly high $S_{P t}$ value of $45 \mathrm{~m}^{2} \mathrm{~g}_{\mathrm{Pt}}{ }^{-1}$. This value is almost 3 times higher than that obtained after post-treatment in $\mathrm{H}_{2} / \mathrm{N}_{2}$. This significant difference is probably the consequence of the weaker chemisorption of hydrogen on PtSn due to strain and ligand effects.

Sample I-8, obtained after UV irradiation, calcination in a $\mathrm{H}_{2} / \mathrm{N}_{2}$ and annealing in air, exhibits no ORR activity. Yet its structure and morphology appear promising (metallic Pt was detected by XRD and good dispersion of Pt nanoparticles was observed by TEM). This absence of ORR activity after annealing in air may be due to the reoxidation of Sn atoms around $\mathrm{Pt}$ nanoparticles, or to the encapsulation of the Pt nanoparticles by $\mathrm{Sn}$, restricting the access to Pt nanoparticles in both cases.

Electrocatalyst I-7 (UV irradiation + calcination in air) is the only sample from the incipient wetness impregnation method that shows a higher $S_{\mathrm{Pt}}$ than Pt/ATO obtained from the EG method $\left(45 \mathrm{~m}^{2} \mathrm{~g}_{\mathrm{Pt}}{ }^{-1}\right.$ vs. $32 \mathrm{~m}^{2} \mathrm{gPt}^{-1}$ ).

Depending on the post-treatment, the incipient wetness impregnation method resulted in various but overall lower ORR mass activities compared to the EG method (see Table II).

In agreement with very low $S_{\mathrm{Pt}}$ values, the ORR mass activities of samples I-3 and I-8 were too low to be measured. As stated above, on the one hand a single UV irradiation (I-3) is not sufficient to 

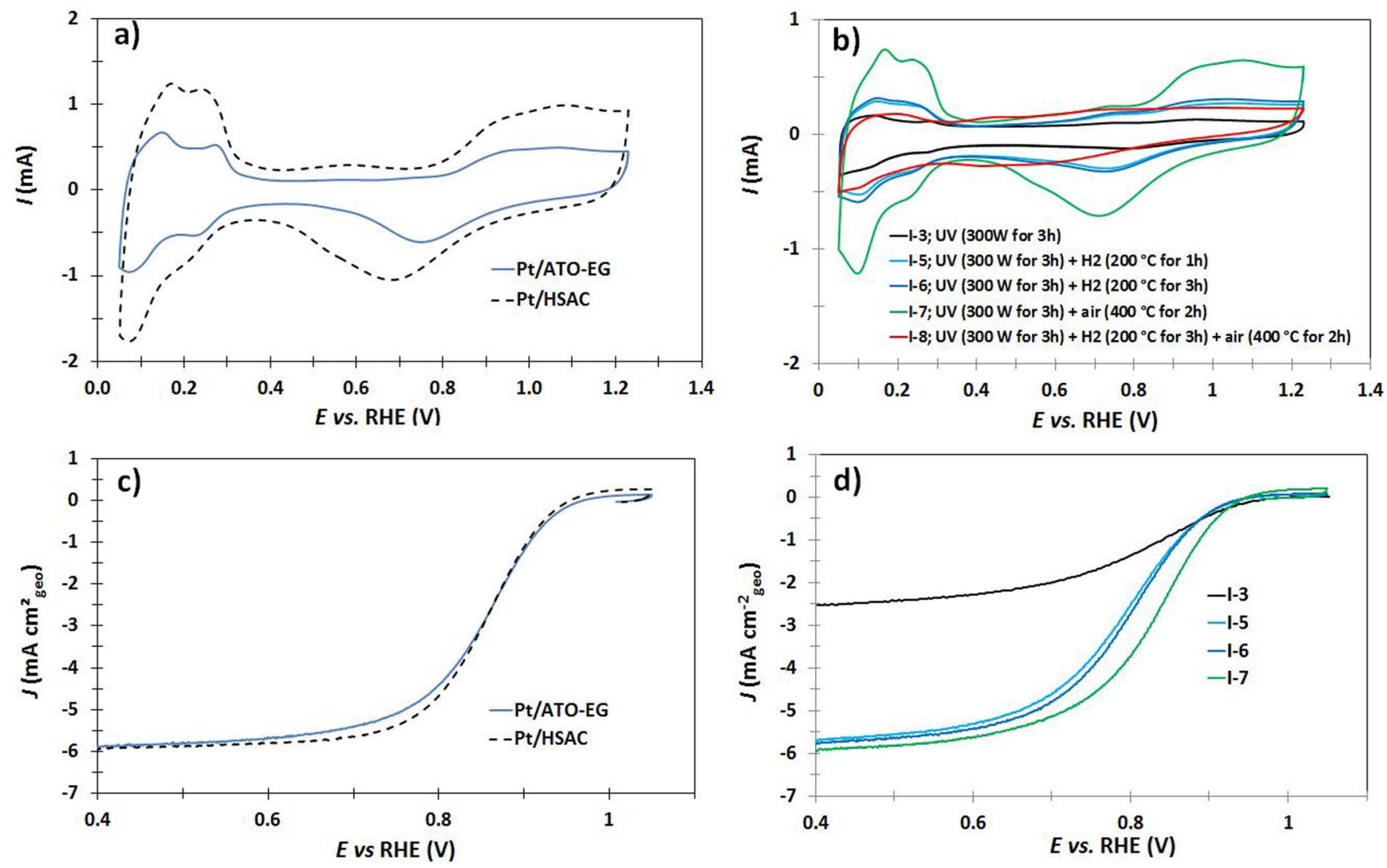

Figure 6. (a, b) Base cyclic voltammograms (Ar-saturated, $0.1 \mathrm{M} \mathrm{H}_{2} \mathrm{SO}_{4}$ ) and (c, d) ORR polarization curves $\left(\mathrm{O}_{2}\right.$-saturated, $\left.0.1 \mathrm{M} \mathrm{H}_{2} \mathrm{SO}_{4}\right)$ measured on $\mathrm{Pt} / \mathrm{ATO}-\mathrm{EG}, \mathrm{Pt} / \mathrm{HSAC}$ and Pt/ATO-I samples. The ORR measurements were performed at a potential sweep rate $v=0.005 \mathrm{~V} \mathrm{~s}^{-1}$ and a rotating speed $1,600 \mathrm{rpm}$. Positive-going potential sweep from 0.40 to $1.05 \mathrm{~V}$ vs. RHE; $T=25^{\circ} \mathrm{C}$.

reduce $\mathrm{Pt}$ nanoparticles, and on the other hand, annealing in air after calcination in $\mathrm{H}_{2} / \mathrm{N}_{2}$ (I-8) probably resulted in the encapsulation of $\mathrm{Pt}$ nanoparticles by $\mathrm{SnO}_{2}$ after re-oxidation of PtSn.

Although a slight difference was observed in $S_{\mathrm{Pt}}$ after different calcination durations in $\mathrm{H}_{2} / \mathrm{N}_{2}$ following UV irradiation (I-5 vs. I-6), in general the longer the calcination time, the higher the ORR mass activity. Moreover, it is noteworthy that the ORR mass activity of sample I-6 (3 h of calcination) approaches that of Pt/HSAC (22 A $\mathrm{g}_{\mathrm{Pt}}{ }^{-1}$ vs. $\left.27 \mathrm{~A} \mathrm{~g}_{\mathrm{Pt}}{ }^{-1}\right)$.

The sample post-treated in air (I-7) features the highest $S_{\mathrm{Pt}}$ and a ORR mass activity approaching that of the reference Pt/HSAC (21 A $\mathrm{g}_{\mathrm{Pt}}{ }^{-1}$ vs. $\left.27 \mathrm{~A} \mathrm{~g}_{\mathrm{Pt}}{ }^{-1}\right)$. Despite this much higher $\mathrm{S}_{\mathrm{Pt}}$, its mass activity remains similar to that obtained after post-treatment in $\mathrm{H}_{2} / \mathrm{N}_{2}$ (I-6). This can be interpreted by considering that calcination in air likely increases the Pt crystallinity level sufficiently to permit $\mathrm{H}_{\text {upd }}$, but not enough to efficiently catalyze the ORR. This is consistent with the

Table II. Electrochemical characterization results (RDE).

\begin{tabular}{clcc} 
Samples & \multicolumn{1}{c}{$\begin{array}{c}\text { Reduction routes and heat } \\
\text { treatments }\end{array}$} & $\begin{array}{c}\mathrm{S}_{\mathrm{Pt}} \\
\left(\mathrm{m}^{2} \mathrm{gPt}^{-1}\right)\end{array}$ & $\begin{array}{c}\mathrm{MA}_{0.9 \mathrm{~V}} \\
\left(\mathrm{~A} \mathrm{gt}_{\mathrm{Pt}}{ }^{-1}\right)\end{array}$ \\
\hline Pt/HSAC & & 72 & 27 \\
EG & Chemical reduction & 32 & 32 \\
I-3 & $\mathrm{UV}(300 \mathrm{~W}, 3 \mathrm{~h})$ & 6 & - \\
$\mathrm{I}-5$ & $\mathrm{UV}(300 \mathrm{~W}, 3 \mathrm{~h})+\mathrm{H}_{2}\left(200^{\circ} \mathrm{C}, 1 \mathrm{~h}\right)$ & 13 & 14 \\
$\mathrm{I}-6$ & $\mathrm{UV}(300 \mathrm{~W}, 3 \mathrm{~h})+\mathrm{H}_{2}\left(200^{\circ} \mathrm{C}, 3 \mathrm{~h}\right)$ & 14.5 & 22 \\
$\mathrm{I}-7$ & $\mathrm{UV}(300 \mathrm{~W}, 3 \mathrm{~h})+$ air $\left(400^{\circ} \mathrm{C}, 2 \mathrm{~h}\right)$ & 45 & 21 \\
I-8 & $\mathrm{UV}(300 \mathrm{~W}, 3 \mathrm{~h})+\mathrm{H}_{2}\left(200^{\circ} \mathrm{C}, 3 \mathrm{~h}\right)$ & 3 & -
\end{tabular}

XRD patterns, in which no crystalline Pt could be detected on the samples (see Figure 2).

Thermal post-treatment is necessary to activate $\mathrm{Pt}$ nanoparticles after photoreduction. Calcination in $\mathrm{H}_{2} / \mathrm{N}_{2}\left(200^{\circ} \mathrm{C}, 3 \mathrm{~h}\right)$ or air $\left(400^{\circ} \mathrm{C}\right.$, $2 \mathrm{~h}$ ) resulted in similar ORR mass-activity, the latter showing a much higher $S_{\mathrm{Pt}}$ value.

To summarize, different Pt/ATO aerogel electrocatalysts were synthesized and electrochemically characterized using the RDE technique. The highest Pt specific surface area $\left(S_{\mathrm{Pt}}\right)$ was obtained with the incipient wetness impregnation method, after UV irradiation and post-treatment in air (I-7), while the highest ORR mass activity was obtained with the EG method. The latter even exceeds that of the commercial carbon-based electrocatalyst taken as reference (Pt/HSAC).

Durability.-Owing to its better ORR activity, Pt/ATO-EG was selected for durability tests. The accelerated stress test (AST) performed was composed of 5,000 potential cycles with a square-wave profile between 1.0 and $1.5 \mathrm{~V}$ vs. RHE (holding time of $t=3 \mathrm{~s}$ at each potential, $T=80^{\circ} \mathrm{C}$ ). This AST mimics the potential values experienced by a PEMFC cathode electrocatalyst during start/stop of the PEMFC system or fuel-starvation events. The temperature chosen for the AST was $80^{\circ} \mathrm{C}$, since it mimics the changes in morphology and surface reactivity occurring on Pt nanoparticles in a real PEMFC environment, as recently shown in Ref. 53. The AST and the electrochemical characterizations (base CVs and ORR polarization curves) were performed in two different electrochemical cells: this procedure guarantees the determination of the true ORR kinetics without any adverse interference of metallic ions, which could be released during the AST. ${ }^{54}$ The electrolyte composition was not changed in the AST cell, but replaced with fresh electrolyte for each intermediate characterization in the "characterization" cell. For the sake of reproducibility, the 

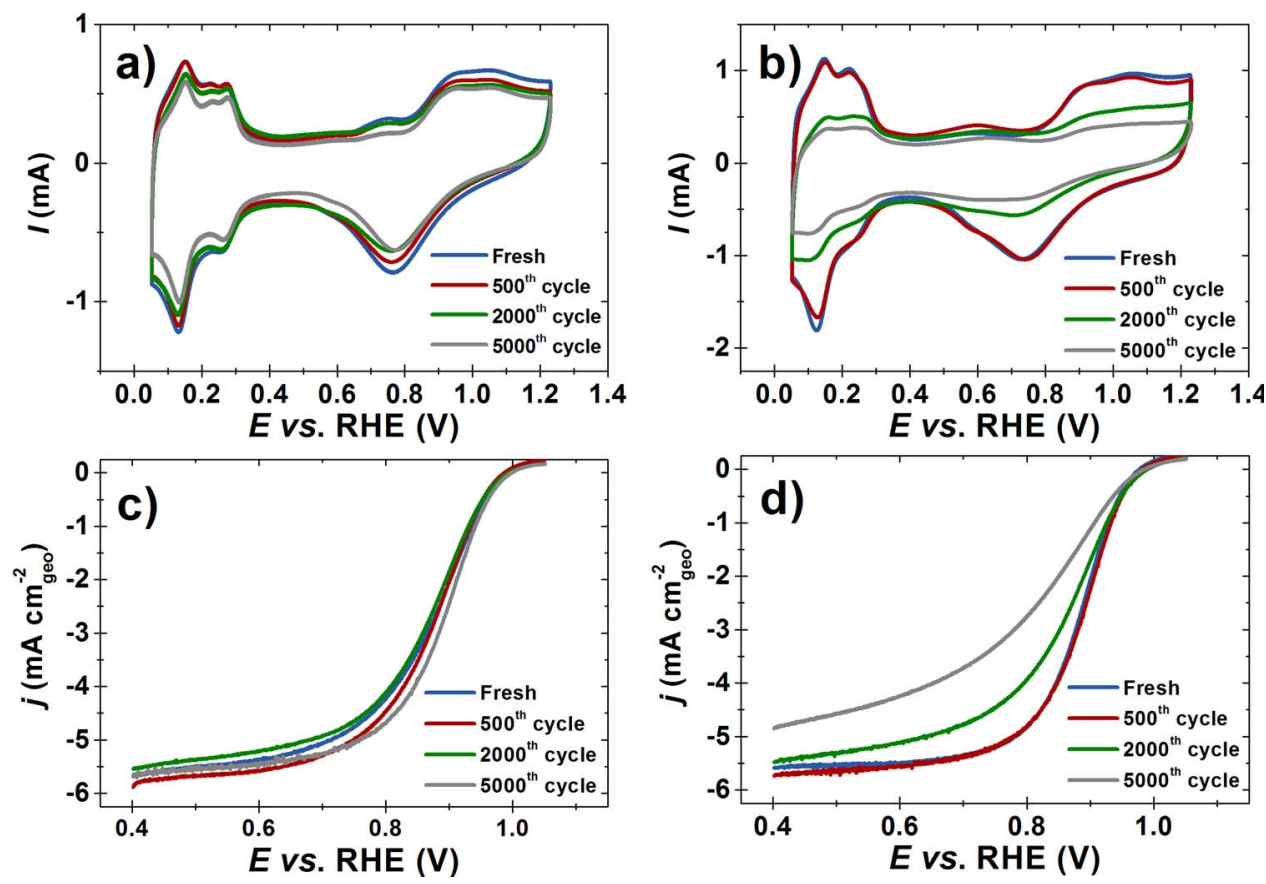

Figure 7. Changes of the base CVs and ORR polarization curves during an AST composed of 5,000 potential cycles with a square-wave profile between 1.0 and $1.5 \mathrm{~V}$ vs. RHE at $T=80^{\circ} \mathrm{C}$ for Pt/ATO-EG (a, c) and Pt/HSAC (b, d). The ORR measurements were performed in $\mathrm{O}_{2}$-saturated $0.1 \mathrm{M} \mathrm{H}_{2} \mathrm{SO}_{4}$ at a potential sweep rate $v=0.005 \mathrm{~V} \mathrm{~s}^{-1}$, a rotating speed $1,600 \mathrm{rpm}$ and a temperature $T=25 \pm 1^{\circ} \mathrm{C}$. Positive-going potential sweep from 0.40 to $1.05 \mathrm{~V}$ vs. RHE.

measurements were performed three times on each catalyst (the error bars represent the standard deviation).

The intermediate CVs recorded during the AST are displayed in Figure 7. The homothetic depreciation of the coulometry required to adsorb/desorb $\mathrm{H}_{\text {upd }}$ and form surface oxides on the Pt/HSAC electrocatalyst clearly suggests that most of the initial ECSA was lost. The pseudo-capacitance of the electrode did not vary significantly during the AST potential cycles, thereby suggesting that the Pt nanoparticles simply detached from the HSAC support, in agreement with former findings on the same catalyst. ${ }^{14}$ On Pt/ATO, the variations of the base CVs and ORR polarization curves were smaller. Figure 7a illustrates the loss of $S_{\mathrm{Pt}}$ on Pt/HSAC: (i) the ORR polarization curve shifted toward more negative electrode potential and (ii) the diffusion-limited current decreased. In agreement with model studies on $\mathrm{Pt} / \mathrm{C}$ by $\mathrm{Ru}-$ vinskiy et al..$^{55}$ and Dong et al. ${ }^{56}$ these changes reflect the decreased density of $\mathrm{O}_{2}$ adsorption sites in the electrode.

The variations in $\mathrm{Pt}$ specific surface area, relative to the initial value recorded for $\mathrm{Pt} / \mathrm{HSAC}$, are monitored against the number of potential cycles in Figure 8a. After 5,000 potential cycles between 1.0 and $1.5 \mathrm{~V}$ vs. RHE, $75 \%$ of the initial $S_{\mathrm{Pt}}$ was lost for the Pt/HSAC electrocatalyst. Meanwhile, the initial $S_{\mathrm{Pt}}$ decreased by only $33 \%$ on $\mathrm{Pt} / \mathrm{ATO}-\mathrm{EG}$. Hence, despite a lower $S_{\mathrm{Pt}}$ value at the beginning of the test (most likely resulting from the presence of filaments, see Figure 1), Pt/ATO-EG is more robust in experimental conditions critical to carbon supports. The advantage in Pt specific surface area also prevails in terms of electrocatalytic activity for the ORR: both the initial and the long-term ORR specific activities are slightly larger on the $\mathrm{Pt} / \mathrm{ATO}-\mathrm{EG}$ electrocatalyst than on the reference Pt/HSAC electrocatalyst. Because of the smaller Pt specific surface area, both materials performed identically in terms of ORR mass activity, in agreement with our former findings. ${ }^{30}$ However, due to the pronounced detachment of Pt nanoparticles from the HSAC support, the electrocatalytic advantage of Pt/ATO-EG was enhanced after the AST. After 5,000 potential cycles between 1.0 and $1.5 \mathrm{~V}$ vs. RHE, the Pt/ATO-EG electrocatalyst achieved 1.5-fold and 3-fold enhancement over the reference Pt/HSAC electrocatalyst, in specific and mass activity for the ORR, respectively. These improved ORR performances coupled to the apparent resistance to electrochemical corrosion $\left(S_{\mathrm{Pt}}\right.$ was main- tained) are in line with former literature findings ${ }^{18-20,37}$ and confirm that $\mathrm{Pt} / \mathrm{ATO}-\mathrm{EG}$ is a promising alternative to $\mathrm{Pt} / \mathrm{HSAC}$ for operation at a PEMFC cathode.

\section{Conclusions}

In conclusion, ATO aerogel-based electrocatalysts were prepared using two Pt nanoparticle deposition methods starting from the same Pt salt precursor $\left(\mathrm{H}_{2} \mathrm{PtCl}_{6}\right)$. The first one, labeled EG, is based on a chemical reduction route using ethylene glycol as a solvent and reducing agent, the second one, labeled I, uses UV irradiation to reduce Pt after ATO impregnation with the Pt precursor, followed by different thermal post-treatments.

Electrocatalysts from the EG method exhibit crystalline $\mathrm{Pt}$ nanoparticles, 2-3 nm in size, arranged in the form of filaments composed of agglomerated nanoparticles. The Pt specific surface area reaches $32 \mathrm{~m}^{2} \mathrm{~g}_{\mathrm{Pt}}{ }^{-1}$, about half of that measured for the Pt/HSAC taken as reference $\left(S_{\mathrm{Pt}}=72 \mathrm{~m}^{2} \mathrm{~g}_{\mathrm{Pt}}{ }^{-1}\right)$. Despite this difference, a higher mass activity for the ORR was measured for the Pt/ATO electrocatalyst compared to the Pt/HSAC electrocatalyst $\left(32 \mathrm{~A} \mathrm{~g} \mathrm{gt}^{-1} \mathrm{vs}\right.$. $27 \mathrm{~A} \mathrm{~g}_{\mathrm{Pt}}{ }^{-1}$, respectively).

The electrocatalysts prepared with the incipient wetness impregnation method led, after the UV irradiation step, to Pt nanoparticles ca. $2-3 \mathrm{~nm}$ in size, perfectly distributed on the surface of the support. However, no peak characteristic of crystalline Pt was detected by X-ray diffraction.

Reduction by heat-treatment under a reducing atmosphere $\left(\mathrm{H}_{2} / \mathrm{N}_{2}\right)$ led to crystalline Pt nanoparticles, which were however too large $(7-8 \mathrm{~nm})$ for the foreseen application; these nanoparticles also present evidence of the formation of a PtSn intermetallic compound (and/or encapsulation of the Pt nanoparticles by $\mathrm{Sn}$ ) that is detrimental to electrocatalysis.

The influence of thermal post-treatments after the UV irradiation, under either a reducing or an oxidizing atmosphere was also investigated. Whatever the nature of the thermal treatment, few differences were observed in terms of particle size and distribution on the ATO surface. However, thermal treatments have an important influence on 

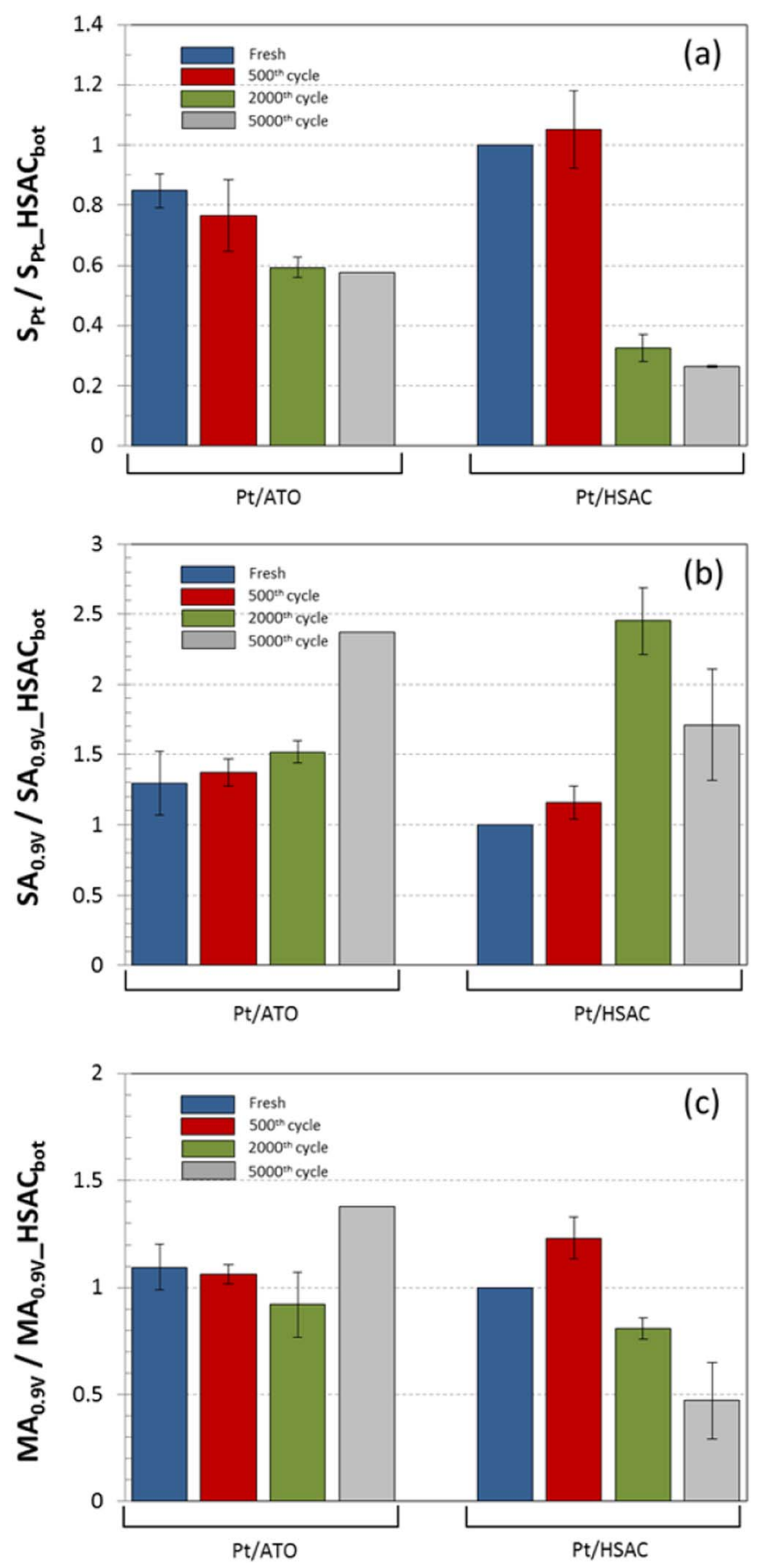

Figure 8. Changes in the Pt specific surface area (a), specific activity (b) and mass activity for the ORR measured at $E=0.90 \mathrm{~V}$ vs. RHE (c), relative to that of Pt/HSAC at the beginning of the test (bot) for Pt/ATO-EG and $\mathrm{Pt} / \mathrm{HSAC}$ during an AST composed of 5,000 potential cycles with a squarewave profile between 1.0 and $1.5 \mathrm{~V}$ vs. RHE at $80^{\circ} \mathrm{C}$. The ORR measurements were performed in $\mathrm{O}_{2}$-saturated $0.1 \mathrm{M} \mathrm{H}_{2} \mathrm{SO}_{4}$ at a potential sweep rate $v=$ $0.005 \mathrm{~V} \mathrm{~s}^{-1}$, a rotating speed $1,600 \mathrm{rpm}$ and a temperature $T=25 \pm 1^{\circ} \mathrm{C}$. Positive-going potential sweep from 0.40 to $1.05 \mathrm{~V}$ vs. RHE.

the nanoparticles' structure. After a heat-treatment in a reducing atmosphere, an intermetallic compound PtSn was detected. This compound is re-oxidized after annealing in an oxidizing atmosphere.

After a single photoreduction step, no electrocatalytic activity for the ORR was monitored. This is probably due to the poor crystallinity of the Pt nanoparticles.

Although the largest Pt specific surface area was obtained when a calcination step in oxidizing atmosphere followed the photoreduction step $\left(S_{\mathrm{Pt}}=45 \mathrm{~m}^{2} \mathrm{~g}_{\mathrm{Pt}}{ }^{-1}\right)$, the highest ORR mass activity was obtained after calcining the UV irradiated Pt/ATO in a reducing atmosphere $\left(\mathrm{MA}_{0.9 \mathrm{~V}}=22 \mathrm{~A} \mathrm{~g} \mathrm{gt}_{\mathrm{Pt}}{ }^{-1}\right)$. These results suggest that, despite improved Pt specific surface area, Pt was not crystalline enough after calcination in an oxidizing atmosphere to efficiently catalyze the ORR. The best mass activity for the ORR obtained after the incipient wetness impregnation method was therefore still lower than for samples prepared by the EG method or the reference Pt/HSAC. We postulate that this is due to incomplete crystallization/reduction of the Pt salt precursor.

Among the samples compared in this study, Pt/ATO obtained by the EG method possessed the best ORR mass activity. The durability of this electrocatalyst was measured at $80^{\circ} \mathrm{C}$ by applying up to 5,000 potential cycles between 1.0 and $1.5 \mathrm{~V}$ vs. RHE. In these conditions, $\mathrm{Pt} / \mathrm{ATO}$ was much more stable than Pt/HSAC: the carbon-based electrocatalyst lost $50 \%$ of its initial mass activity for the ORR, whereas that of Pt/ATO increased by $25 \%$. In consequence, ATO aerogels prove to be credible alternatives to high-surface area carbon blacks for application at a PEMFC cathode. Further work will now be dedicated to their evaluation in a membrane electrode assembly in real-life PEMFC operating conditions.

\section{Acknowledgments}

The authors thank Pierre Ilbizian for supercritical drying. This work was funded by the French National Research Agency PROGELEC program, (ANR-12-PRGE-007 project SURICAT) and the European Union's Seventh Framework Program for the Fuel Cells and Hydrogen Joint Technology Initiative under grant agreement n325239 (FCH-JU project Nano-CAT). It was supported by Capenergies and Tenerrdis. This work was partly (in LEPMI) performed within the framework of the Centre of Excellence of Multifunctional Architectured Materials "CEMAM" n' AN-10-LABX-44-01. Marian Chatenet thanks the French IUF for its support.

\section{ORCID}

F. Maillard (10) https://orcid.org/0000-0002-6470-8900

M. Chatenet (1) https://orcid.org/0000-0002-9673-4775

C. Beauger (1D) https://orcid.org/0000-0002-6164-1587

\section{References}

1. A. Rabis, P. Rodriguez, and T. J. Schmidt, "Electrocatalysis for Polymer Electrolyte Fuel Cells: Recent Achievements and Future Challenges," ACS Catal, 2, 864 (2012).

2. P. Costamagna and S. Srinivasan, "Quantum jumps in the PEMFC science and technology from the 1960s to the year 2000 Part I. Fundamental scientific aspects," $J$. Power Sources, 102, 242 (2001).

3. M. S. Wilson, F. H. Garzon, K. E. Sickafus, and S. Gottesfeld, "Surface-area loss of supported platinum in polymer electrolyte fuel-cells," J. Electrochem. Soc., 140, $2872(1993)$

4. J. A. Bett, K. Kinoshita, and P. Stonehart, "Crystallite growth of platinum dispersed on graphitized carbon-black," J. Catal., 35, 307 (1974).

5. P. J. Ferreira, G. J. la O', Y. Shao-Horn, D. Morgan, R. Makharia, S. Kocha, an H. A. Gasteiger, "Instability of Pt/C electrocatalysts in proton exchange membrane fuel cells - A mechanistic investigation," J. Electrochem. Soc., 152, A2256 (2005).

6. P. Bindra, S. J. Clouser, and E. Yeager, "Platinum dissolution in concentrated phosphoric-acid," J. Electrochem. Soc., 126, 1631 (1979).

7. X. P. Wang, R. Kumar, and D. J. Myers, "Effect of voltage on platinum dissolution relevance to polymer electrolyte fuel cells," Electrochem. Solid State Lett., 9, A225 (2006).

8. A. Honji, T. Mori, K. Tamura, and Y. Hishinuma, "Agglomeration of platinum particles supported on carbon in phosphoric-acid," J. Electrochem. Soc., 135, 355 (1988).

9. L. M. Roen, C. H. Paik, and T. D. Jarvi, "Electrocatalytic corrosion of carbon support in PEMFC cathodes," Electrochem. Solid State Lett., 7, A19 (2004).

10. S. Maass, F. Finsterwalder, G. Frank, R. Hartmann, and C. Merten, "Carbon support oxidation in PEM fuel cell cathodes," J. Power Sources, 176, 444 (2008).

11. N. Linse, L. Gübler, G. G. Scherer, and A. Wokaun, "The effect of platinum on carbon corrosion behavior in polymer electrolyte fuel cells," Electrochim. Acta., 56 7541 (2011).

12. J. Willsau and J. Heitbaum, "The influence of Pt-activation on the corrosion of carbon in gas-diffusion electrodes - a DEMS study," J. Electroanal. Chem., 161, 93 (1984).

13. L. Castanheira, L. Dubau, M. Mermoux, G. Berthomé, N. Caqué, E. Rossinot, M. Chatenet, and F. Maillard, "Carbon Corrosion in Proton-Exchange Membrane Fuel Cells: From Model Experiments to Real-Life Operation in Membrane Electrode Assemblies," ACS Catal, 4, 2258 (2014). 
14. L. Castanheira, W. O. Silva, F. H. B. Lima, A Crisci, L. Dubau, and F. Maillard, "Carbon Corrosion in Proton-Exchange Membrane Fuel Cells: Effect of the Carbon Structure, the Degradation Protocol, and the Gas Atmosphere," ACS Catal, 5, 2184 (2015)

15. C. A. Reiser, L. Bregoli, T. W. Patterson, J. S. Yi, J. D. L. Yang, M. L. Perry, and T. D. Jarvi, "A reverse-current decay mechanism for fuel cells," Electrochem. Solid State Lett., 8, A273 (2005).

16. G. Maranzana, C. Moyne, J. Dillet, S. Didierjean, and O. Lottin, "About internal currents during start-up in proton exchange membrane fuel cell," J. Power Sources, 195, 5990 (2010).

17. B. K. Honga, P. Mandala, J. Oh, and S. Litster, "On the impact of water activity on reversal tolerant fuel cell anode performance and durability," J. Power Sources, 328, 280 (2016).

18. A. Masao, S. Noda, F. Takasaki, K. Ito, and K. Sasaki, "Carbon-Free Pt Electrocatalysts Supported on $\mathrm{SnO}_{2}$ for Polymer Electrolyte Fuel Cells," Electrochem. Solid State Lett., 12, B119 (2009).

19. Y. Takabatake, Z. Noda, S. M. Lyth, A. Hayashi, and K. Sasaki, "Cycle durability of metal oxide supports for PEFC electrocatalysts," Int. J. Hydrogen Energy, 39, 5074 (2014).

20. P. Zhang, S.-Y. Huang, and B. N. Popov, "Mesoporous Tin Oxide as an OxidationResistant Catalyst Support for Proton Exchange Membrane Fuel Cells," J. Electrochem. Soc., 157, B1163 (2010)

21. G. Ozouf and C. Beauger, "Niobium- and antimony-doped tin dioxide aerogels as new catalyst supports for PEM fuel cells," J. Mater. Sci., 51, 5305 (2016)

22. V. Gokulakrishnan, S. Parthiban, K. Jeganathan, and K. Ramamurthi, "Investigations on the structural, optical and electrical properties of Nb-doped $\mathrm{SnO}_{2}$ thin films," $J$ Mater. Sci., 46, 5553 (2011).

23. D. Szczuko, J. Werner, S. Oswald, G. Behr, and K. Wetzig, "XPS investigations of surface segregation of doping elements in $\mathrm{SnO}_{2}$," Appl. Surf. Sci., 179, 301 (2001).

24. E. R. Leite, I. T. Weber, E. Longo, and J. A. Varela, "A new method to control particle size and particle size distribution of $\mathrm{SnO}_{2}$ nanoparticles for gas sensor applications," Adv. Mater., 12, 965-+ (2000)

25. F. Takasaki, S. Matsuie, Y. Takabatake, Z. Noda, A. Hayashi, Y. Shiratori, K. Ito, and K. Sasaki, "Carbon-Free Pt Electrocatalysts Supported on $\mathrm{SnO}_{2}$ for Polyme Electrolyte Fuel Cells: Electrocatalytic Activity and Durability," J. Electrochem. Soc., 158, B1270 (2011)

26. K. Kakinuma, Y. Chino, Y. Senoo, M. Uchida, T. Kamino, H. Uchida, S. Deki, and M. Watanabe, "Characterization of Pt catalysts on $\mathrm{Nb}$-doped and Sb-doped $\mathrm{SnO}_{2}$ delta support materials with aggregated structure by rotating disk electrode and fuel cell measurements," Electrochim. Acta, 110,316 (2013).

27. S. Cavaliere, S. Subianto, I. Savych, M. Tillard, D. J. Jones, and J. Rozière, "DopantDriven Nanostructured Loose-Tube $\mathrm{SnO}_{2}$ Architectures: Alternative Electrocatalys Supports for Proton Exchange Membrane Fuel Cells," J. Phys. Chem. C, 117, 18298 (2013)

28. S. Shahgaldi and J. Hamelin, "The effect of low platinum loading on the efficiency of PEMFC's electrocatalysts supported on $\mathrm{TiO}_{2}-\mathrm{Nb}$, and $\mathrm{SnO}_{2}-\mathrm{Nb}$ : An experimental comparison between active and stable conditions," Energy Convers. Management, 103, 681 (2015).

29. G. Ozouf, G. Cognard, F. Maillard, L. Guétaz, M. Heitzmann, and C. Beauger, "SnO Aerogels: Towards Performant and Stable PEFC Catalyst Supports," ECS Trans., 69, 1207 (2015).

30. G. Cognard, G. Ozouf, C. Beauger, G. Berthomé, D. Riassetto, L. Dubau, R. Chattot, M. Chatenet, and F. Maillard, "Benefits and limitations of Pt nanoparticles supported on highly porous antimony-doped tin dioxide aerogel as alternative cathode material for proton-exchange membrane fuel cells." Appl. Catal. B, 201, 381 (2017).

31. K. Kakinuma, M. Uchida, T. Kamino, H. Uchida, and M. Watanabe, "Synthesis and electrochemical characterization of Pt catalyst supported on $\mathrm{Sn}_{0.96} \mathrm{Sb}_{0.04} \mathrm{O}_{2}$-delta with a network structure," Electrochim. Acta, 56, 2881 (2011).

32. M. P. Gurrola, M. Guerra-Balcazar, L. Alvarez-Contreras, R. Nava J. Ledesma-Garcia, and L. G. Arriaga, "High surface electrochemical support based on Sb-doped $\mathrm{SnO}_{2}$," J. Power Sources, 243, 826 (2013).

33. D. J. You, K. Kwon, C. Pak, and H. Chang, "Platinum-antimony tin oxide nanoparticle as cathode catalyst for direct methanol fuel cell," Catal. Today, 146, 15, (2009)

34. M. Yin, J. Y. Xu, G. F. Li, J. O. Jensen, Y. J. Huang, L. N. Cleemann, N. J. Bjerrum, and W. Xing, "Highly active and stable Pt electrocatalysts promoted by antimonydoped $\mathrm{SnO}_{2}$ supports for oxygen reduction reactions," Appl. Catal. B., 144, 112 (2014)
35. H. S. Oh, H. N. Nong, and P. Strasser, "Preparation of Mesoporous Sb-, F-, and InDoped $\mathrm{SnO}_{2}$ Bulk Powder with High Surface Area for Use as Catalyst Supports in Electrolytic Cells," Adv. Funct. Mater, 25, 1074 (2015).

36. V. Avila-Vazquez, M. Galvan-Valencia, J. Ledesma-Garcia, L. G. Arriaga, V. H. Collins-Martinez, C. Guzman-Martinez, I. L. Escalante-Garcia, and S. M. Duron-Torres, "Electrochemical performance of a Sb-doped $\mathrm{SnO}_{2}$ support synthesized by coprecipitation for oxygen reactions," J. Appl. Electrochem., 45, 1175 (2015).

37. E. Fabbri, A. Rabis, R. Kotz, and T. J. Schmidt, "Pt nanoparticles supported on Sbdoped $\mathrm{SnO}_{2}$ porous structures: developments and issues," Phys. Chem. Chem. Phys., 16, $13672(2014)$.

38. Y. Senoo, K. Taniguchi, K. Kakinuma, M. Uchida, H. Uchida, S. Deki, and M. Watanabe, "Cathodic performance and high potential durability of $\mathrm{Ta}-\mathrm{SnO}_{2 \text {-delta }}$ supported Pt catalysts for PEFC cathodes," Electrochem. Commun., 51, 37 (2015).

39. S. J. Tauster and S. C. Fung, "Strong metal-support interactions - occurrence among binary oxides og groups IIA-VB," J. Catal., 55, 29 (1978).

40. N. Kamiuchi, T. Matsui, R. Kikuchi, and K. Eguchi, "Nanoscopic observation of strong chemical interaction between Pt and tin oxide," J. Phys. Chem., 111, 16470 (2007).

41. C. Brieger, J. Melke, N. van der Bosch, U. Reinholz, H. Riesemeier, A. G. Buzanich, M. K. Kayarkatte, I. Derr, A. Schokel, and C. Roth, "A combined in-situ XASDRIFTS study unraveling adsorbate induced changes on the Pt nanoparticle structure," J. Catal., 339, 57 (2016).

42. M. S. Spencer, "Models of strong metal support interaction (SMSI) in Pt on $\mathrm{TiO}_{2}$ catalysts," J. Catal., 93, 216 (1985).

43. T. Daio, A. Staykov, L. M. Guo, J. F. Liu, M. Tanaka, S. M. Lyth, and K. Sasaki, "Lattice Strain Mapping of Platinum Nanoparticles on Carbon and $\mathrm{SnO}_{2}$ Supports," Sci. Reports, 5, 10 (2015)

44. M. Ouattara-Brigaudet, C. Beauger, S. Berthon-Fabry, and P. Achard, "Carbon Aerogels as Catalyst Supports and First Insights on Their Durability in Proton Exchange Membrane Fuel Cells," Fuel Cells, 11, 726 (2011).

45. M. Ouattara-Brigaudet, S. Berthon-Fabry, C. Beauger, M. Chatenet, N. Job, M. Sennour, and P. Achard, "Influence of the carbon texture of platinum/carbon aerogel electrocatalysts on their behavior in a proton exchange membrane fuel cell cathode." Int. J. Hydrogen Energy, 37, 9742 (2012)

46. K. S. Lee, I. S. Park, Y. H. Cho, D. S. Jung, N. Jung, H. Y. Park, and Y. E. Sung, "Electrocatalytic activity and stability of Pt supported on Sb-doped $\mathrm{SnO}_{2}$ nanoparticles for direct alcohol fuel cells," J. Catal., 258, 143 (2008).

47. A. Oliveira Neto, M. Brandalise, R. R. Dias, J. M. S. Ayoub, A. C. Silva, J. C. Penteado, M. Linardi, and E. V. Spinace, "The performance of Pt nanoparticles supported on $\mathrm{Sb}_{2} \mathrm{O}_{5} \mathrm{SnO}_{2}$, on carbon and on physical mixtures of $\mathrm{Sb}_{2} \mathrm{O}_{5}$ center dot $\mathrm{SnO}_{2}$ and carbon for ethanol electro-oxidation," Int. J. Hydrogen. Energy, 35, 9177 (2010).

48. C. Q. Pan, Y. Z. Li, Y. H. Ma, X. Zhao, and Q. H. Zhang, "Platinum-antimony doped tin oxide nanoparticles supported on carbon black as anode catalysts for direct methanol fuel cells," J. Power Sources, 196, 6228 (2011).

49. D. J. Guo, "Electrooxidation of ethanol on novel multi-walled carbon nanotube supported platinum-antimony tin oxide nanoparticle catalysts," J. Power Sources, 196, 679 (2011).

50. F. Micoud, F. Maillard, A. Bonnefont, N. Job, and M. Chatenet, "The role of the support in COads monolayer electrooxidation on Pt nanoparticles: Pt/WOx vs. Pt/C," Phys. Chem. Chem. Phys., 12, 1182 (2010)

51. J. C. Yang, Y C. Kim, Y G. Shul, C. H Shin, and T. K. Lee, "Characterization of photoreduced $\mathrm{Pt} / \mathrm{TiO}_{2}$ and decomposition of dichloroacetic acid over photoreduced $\mathrm{Pt} / \mathrm{TiO}_{2}$ catalysts," Appl. Surf. Sci., 121, 525 (1997).

52. F. Maillard, M. Eikerling, O. V. Cherstiouk, S. Schreler, E. Savinova, and U. Stimming, "Size effects on reactivity of Pt nanoparticles in CO monolayer oxidation: The role of surface mobility," Faraday Discuss, 125, 357 (2004).

53. L. Dubau and F. Maillard, "Unveiling the crucial role of temperature on the stability of oxygen reduction reaction electrocatalysts," Electrochem. Commun., 63, 65 (2016).

54. J. Durst, M. Chatenet, and F. Maillard, "Impact of metal cations on the electrocatalytic properties of Pt/C nanoparticles at multiple phase interfaces," Phys. Chem. Chem. Phys., 14, 13000 (2012).

55. P. S. Ruvinskiy, A. Bonnefont, M. Houlle, C. Pham-Huu, and E. R. Savinova, "Preparation, testing and modeling of three-dimensionally ordered catalytic layers for electrocatalysis of fuel cell reactions," Electrochim. Acta, 55, 3245 (2010).

56. Q. Dong, S. Santhanagopalan, and R. E. White, "Simulation of the oxygen reduction reaction at an RDE in $0.5 \mathrm{~m} \mathrm{H}_{2} \mathrm{SO}_{4}$ including an adsorption mechanism," $J$. Electrochem. Soc., 154, A888 (2007). 